\title{
TU/e EmonOWEN

\section{Feeding a monster or doing good? Mining industrial design student feedback at large}

\section{Citation for published version (APA):}

Funk, M., \& Diggelen, van, M. R. (2014). Feeding a monster or doing good? Mining industrial design student feedback at large. In H. M. Fardoun, \& J. S. Gallud (Eds.), 2014 Workshop on Interaction Design in Educational Environments (IDEE '14), June 9, 2014, Albacete, Spain. (pp. 59-63). (ACM International Conference Proceeding Series). Association for Computing Machinery, Inc. https://doi.org/10.1145/2643604.2643630

DOI:

10.1145/2643604.2643630

Document status and date:

Published: 01/01/2014

\section{Document Version:}

Publisher's PDF, also known as Version of Record (includes final page, issue and volume numbers)

\section{Please check the document version of this publication:}

- A submitted manuscript is the version of the article upon submission and before peer-review. There can be important differences between the submitted version and the official published version of record. People interested in the research are advised to contact the author for the final version of the publication, or visit the $\mathrm{DOI}$ to the publisher's website.

- The final author version and the galley proof are versions of the publication after peer review.

- The final published version features the final layout of the paper including the volume, issue and page numbers.

Link to publication

\section{General rights}

Copyright and moral rights for the publications made accessible in the public portal are retained by the authors and/or other copyright owners and it is a condition of accessing publications that users recognise and abide by the legal requirements associated with these rights.

- Users may download and print one copy of any publication from the public portal for the purpose of private study or research.

- You may not further distribute the material or use it for any profit-making activity or commercial gain

- You may freely distribute the URL identifying the publication in the public portal.

If the publication is distributed under the terms of Article 25fa of the Dutch Copyright Act, indicated by the "Taverne" license above, please follow below link for the End User Agreement:

www.tue.nl/taverne

Take down policy

If you believe that this document breaches copyright please contact us at:

openaccess@tue.nl

providing details and we will investigate your claim. 


\section{Feeding a monster or doing good? Mining Industrial Design Student Feedback at Large}

\author{
Mathias Funk \\ Department of Industrial Design, \\ Eindhoven University of Technology \\ Eindhoven, The Netherlands \\ m.funk@tue.nl
}

\author{
Migchiel van Diggelen \\ Department of Industrial Design \\ Eindhoven University of Technology \\ Eindhoven, The Netherlands \\ m.v.diggelen@tue.nl
}

\begin{abstract}
In this paper, we describe work in progress, a study of a large database of written university teacher feedback given to Industrial Design students throughout the semester, over several years. This large corpus is captured technically in a database, but conceptually organized into several feedback moments per semester, which will be analyzed using a newly developed framework targeting Industrial Design education at the university level. Essential aspects of this paper focus on the translation of related work in the area of feedback mechanisms for higher education into a tailored framework for feedback in the area of Industrial Design, and the translation of the existing corpus of data into indicators of feedback quality and how feedback is received and further on used by students in their learning process. Outcomes will be used to further investigate how the quality of feedback evolves and to develop better tools for feedback. With this paper we aim at opening the discussion about our intended process and methodology, as well as inspiration for aspects we have missed so far.
\end{abstract}

\section{Keywords}

Educational Data Mining, Learning Analytics, Industrial Design, Feedback, Teaching Quality.

\section{INTRODUCTION}

Feedback is a crucial way to facilitate students' development as independent learners [1]. Accordingly, students of the department of Industrial Design at the Eindhoven University of Technology (TU/e) frequently receive written feedback from their teachers, i.e. assignors and lecturers of modules. Despite the potential power of feedback [2, 3], there are concerns regarding the perceived lack of impact of written feedback on practice [3]. It is argued that written feedback is often unclear and deficient in quality [5].

\subsection{CONTEXT}

In the department of Industrial Design (ID), these concerns are recognized by teachers and educational policy makers. The written feedback can be characterized by, for example, (1) confusing and unclear focus of feedback, and (2) not enough informative feedback that is personally specific and not generally about the course or teaching activity. Thus, it is likely that feedback provided by lecturers and assignors is less powerful than intended, which clearly limits students in their possibilities for learning and developing their skills, attitude and knowledge [1]). What was intended as a lively feedback process, a dialogue between teacher and student, had, for structural, technical and also administrative reasons to be reduced to a rather meager one-way process. Therefore, lecturers and assignors can strongly benefit from knowledge and insights on how they and others write feedback, how feedback inter-subjectively compares, and how the feedback is received by students.

\subsection{GOALS}

Against this background a project was started to perform a largescale analysis of teacher feedback in the Industrial Design department, addressing more specifically also the challenge of mining semi- or unstructured free-text feedbacks of teachers of various professional and cultural backgrounds. This involves tackling the amount of data provided, which clearly calls for automated analysis, or at least very good filtering in a preprocessing step before manual analysis, but also, the encoding of information given in individual feedbacks needs to be translated to a common framework that then will be used to provide common indicators of feedback quality.

This paper reports on the first phase in this larger project, leaving the large-scale data analysis partly aside and reporting primarily on the framework mentioned above. Goals of this initial phase were twofold: firstly, to develop a framework, as a category system for analyzing written feedback forms in a digital database. Secondly, this framework was then translated to indicators that can easily be derived from the larger feedback corpus - in an automated manner.

Through this study we intend to contribute to the fields of learning analytics and educational data mining, but most to the growing body of research on feedback mechanisms and feedback quality assessment in higher education with a specific focus on Industrial Design. In this study, therefore, the following research question will be answered: How can highly diverse unstructured teacher feedback in the domain of Industrial Design education be analyzed collectively using a common descriptive and structured framework?

In the remaining parts of the paper, related work is introduced, before the main conceptual framework is presented and discussed how general feedback literature can be translated towards this framework. After that, the second part, the quality indicators will be explained and discussed as well. The paper concludes with a discussion and outline of future steps.

\section{RELATED WORK}

In practice, written feedback is used a lot [6]. Despite this frequent use, student surveys have highlighted that students are dissatisfied with the feedback they receive on their assignments [6]. Written feedback is often unclear and deficient in quality and more effort should be put in improving how feedback is formulated [5]. (no follow-up, response or monitoring). To improve the formulation of feedback an understanding of how teachers actually write feedback is important. Surprisingly, there 
are hardly any empirically based category systems available which are funded in (both theory and) practice and are suitable for analysis in the context of data-mining. Fortunately, prevalent models of feedback provide important directions for developing a category system.

One of the prevailing models of feedback is the model of Hattie and Timperley [2]. The authors developed a theoretical model based on their meta-analysis of evidence of the effects of feedback on learning. The authors defined feedback as information provided by an agent regarding aspects of one's performance of understanding. Hattie and Timperley state that effective feedback answers three questions: 'Where am I going?', How am I going?' and 'Where to next?' Answers to these questions provide students with the knowledge about what their learning goals are, how their current understanding or performance relates to these goals and which activities can be undertaken to reach these goals. These questions can be targeted at different levels. These levels are; task, process, regulation and self. Feedback at the task level is used to verify whether something is correct or wrong or how well something is done. Feedback at the process is feedback focused on information processing and processes needed to understand the task. Feedback at the self-regulation level is focused on how students plan, monitor, direct and regulate their thoughts and actions. Finally, feedback at the self is about personal aspects of learning and about positive and negative evaluations of a student. It is important that feedback is focused at the adequate level. Then, feedback will have the most powerful effects on learning. Ideally, the feedback addresses the task level first, the process level next and finally the level of regulation. To target feedback at the adequate level, teachers need to differentiate between these three levels.

Differentiating between different levels of feedback is important, but there is more that constitutes to the effects of feedback on learning: Many researchers consider the form giving of the feedback important as well. Several modalities contribute to the form of feedback. Firstly, the specificity of feedback is important. To be effective, feedback needs to be specific enough to direct the students' learning. Too specific feedback leads to a too narrow focus and often to reproductive forms of learning. It is therefore important that the feedback is specific but not too specific [7]. Secondly, the amount of positive and negative remarks is a key consideration. Generally, teachers have a tendency to be critical and focus their feedback on aspects of the students' learning which need further improvement. However, it is important for teachers to consider both the cognitive and motivational aspects of feedback [6]. Thirdly, it is important that teachers consider how concrete they make their comments. Using concrete and clear wording is mainly focused on behavioral terms. Formulating words too concrete, again, might lead to reproduction, and a lack of conceptualization, creation of meaning, and knowledge transfer. Choosing more abstract language stimulates students to think, conceptualize and make meaning, but being too abstract prevents students from grasping the essence and getting the message across. Again, it seems important not to use too abstract wording and find the right balance. Finally, it is important that the feedback is not too limited. Writing short feedback gives students often the feeling that teachers do not pay enough attention to them, which can demotivate students-especially if they are used to comparatively more extensive feedback by other teachers. Furthermore, limited feedback runs the risk of being unclear and being unspecific with negative consequences for the student's learning processes. On the other hand, being too elaborate prevents students form grasping the essence and understanding the feedback. Elaborate feedback runs the risk of being too specific and distracting from the actual message of the feedback.

To conclude this section, in this project, the following aspects are considered important: the content (constituted by for example task, process and regulation), necessary ingredients (different questions) and form giving (modalities). In the following section, we will condense the selected findings from related research and our own requirements into a conceptual framework that will be used throughout this and further studies.

\section{CONCEPTUAL FRAMEWORK}

The framework presented in this section was derived from - and is still strongly linked to - an extensive body of research on teacher feedback in higher education. The framework will guide the further process of analyzing teacher feedback in the specific context of Industrial Design and a competency-based learning system, but this framework will also point at missing data and insufficient quality measurement that we also strive to improve in the course of this larger-scale project.

\subsection{Method}

The conceptual framework for feedback in the area of Industrial Design, was conceived using an iterative process of going back and forth between theoretical perspectives on feedback and practical perspectives on feedback. The process was started with first exploration of the data that was available, how it was organized and how it could be made accessible to answer more specific queries regarding feedback quality, feedback reception and its use in subsequent student work. After that, a literature review on feedback, written feedback and (written) feedback in higher education was undertaken (without a specific focus on Industrial Design). In the end a framework will be derived from the combination of related research, own reflections and available data, which is presented and shall be used in further iterations of the large-scale feedback improvement project.

\subsection{Resulting Framework}

The resulting framework is comprised by two main categories for written feedback: (1) content and (2) form giving. For both main categories, quality indicators are derived from theory covered in related research and they are used to complete the sub-categories of both main categories.

The first main category is the content of learning. To define the content of learning we constructed a matrix, in which the vertical axis was constituted by the levels of feedback of Hattie and Timperley [2] and important concepts from the educational model of Industrial Design (overall competence of designing, identity and vision). Consequently the following topics are distinguished:

1. Task: comments focused on the goal, standard, ideal situation or indicating whether something is right or wrong

2. Process: comments focused on the information processing and approach a student undertakes

3. Self-regulated and directed learning: comments focused on the orientation, planning, self-assessment, reflection, monitoring regulation and direction of (further) learning

4. Overall competence of Designing comments addressing the overall competence of designing

5. Identity: comments focused on the students personally, motivating and affective aspects of learning but also on whom the student considers him/herself to be as a professional designer or who the student wants to become as a professional designer. 
6. Vision comments focused on why the student wants to be a certain designer and frames what the student wants to learn. These comments can related to values and beliefs and inspire and motivate the student to develop. -

The horizontal axis in this matrix was constituted by different phases of task-oriented learning [8, 9]. Generally, a task is prepared, executed, and ended. During the task-preparation phase, a student is planning and orienting on the task, during the execution the student is performing the task, and during the ending a student is evaluating and reflecting on the task preparation, task performance and results. This reflection is then ideally the basis for a next task's planning phase. Thus, the matrix consisted of 18 cells, which were all filled with a detailed description.

The following quality indicators were considered important for describing the contents:

- Personal: referring to what is already known about the student and her or his previous work

- Contextualised: framed with reference to the learning outcomes and/or assessment criteria

- Forward-looking: suggesting how students might improve subsequent assignments.

Using the quality indicators resulted in descriptions of all 18 cells. The following is a description of providing feedback on the task level during the preparatory phase:

"The coach comments on the characteristics of the task and possible goals (the student puts forward)”.

Providing feedback on the identity level during the ending phase is described as follows: "The coach comments on the students' evaluation and reflection on the importance and meaning of the task-preparation and performance for him/herself (as a designer) and provides suggestions for improving the importance and meaning of the task-performance for him/herself (as a designer) in future situations.”

The second main category is the form giving of feedback. This category encompasses the following subcategories:

- $\quad$ Positive-negative

- $\quad$ Specific-general

- Concrete-abstract

- Limited-elaborate

Based on Nicol [6] the following quality indicators can be used:

- Selective: commenting in reasonable detail on two or three things that the student can do something about.

- Specific: pointing to instances in the student's submission where the feedback applies

- Balanced: pointing out the positive as well as areas in need of improvement.

Using the quality indicators to describe the subcategories leads to the following descriptions:

\section{Positive-negative}

- Mainly pointing out areas for improvement or critiquing. The feedback is mainly negative.

- $\quad$ Mainly pointing out the positive.
- $\quad$ Pointing out the positive as well as areas for improvement. The feedback is balanced in terms of the negative and the positive.

\section{Specific-general}

- Almost no reference to instances in the students' submission where the feedback applies. There is a lack of specificity.

- Too frequent references to instances in the student's submission where the feedback applies. The references distract the reader from the lessons to be learned. The feedback is too specific.

- Reasonable and relevant references to instances in the student's submission where the feedback applies. The mean messages are made clear and specific but not too specific.

Concrete-abstract

- $\quad$ The feedback is mainly phrased in common sense; there is a lack of use and reference to theoretical concepts.

- The feedback is mainly phrased by means of theoretical concepts. There is a lack of clear and understandable language. Theoretical concepts are insufficiently concretized.

- The feedback is sufficiently clear and understandable and framed in theoretical concepts.

Limited-elaborate

- The amount of words used to write the feedback is too limited.

- The amount of words used to write the feedback is too elaborate.

- The amount of words used to write the feedback is not too limited and not too elaborate.

\section{Metrics}

Given the framework as presented above, this section will explain how the concepts will be translated to metrics of feedback quality that can be directly queried with the education database. In this sense, we will approach the framework concepts from view of actual teacher feedback and incrementally define the metrics.

Feedback is provided in forms that are pre-generated, then filled by teachers, and finally fed into a large database. These forms contain different free-text fields for global comments, quality of deliverables, competency development, design process phases, attitude and advice for the student's future learning activities.

For the scoring of the different indicators, single feedback forms can be analyzed, but also multiple feedback forms for the same course (and teacher) can be combined in the analysis. This segmentation of teacher feedback content-wise can be complemented by segmentation by teachers, so particular feedback styles of individual teachers can be analyzed.

\subsection{Content}

Looking at the content of actual teacher feedback, the majority of feedbacks touch the same points content-wise: All teachers are supposed to comment on certain aspects of student learning and growth during a semester. This means that, given a moderately structured text input, algorithms can check for the occurrence of specific words and, in a second step, look at heuristics of word relationships that indicate whether the content of the feedback expanded on all relevant content areas (see above). For instance, for the student's competency development, the text would score high on the specific metric if all relevant competencies are mentioned and they are embedded in relatively large chunks of 
text. More advanced text mining approaches will able to construct ontologies of competency-related word formations, which then can influence the score as well.

\subsection{Form giving}

The form giving of textual feedback is more difficult than looking for specific word and combinations of words: the form giving strives at a deeper understanding of the content: the semantics of what was expressed. There are, however, approaches to derive sentiments from text excerpts that indicate whether a piece of text is generally positive, negative or neutral.

For other metrics in the form giving of feedbacks, the occurrence or non-occurrence of keywords is, again, quite informative: abstract wording can be automatically spotted as well as the mentioning of concrete student deliverables in the feedback can indicate rather general or specific feedback. Similarly, teacher feedback often contains personal aspects, which can be extracted from by leveraging the formal structure or from free-text parts that focus on forward-looking (future-oriented) attitude and advice aspects.

Text quantity is of course comparatively easy to determine: the more the teacher writes in specific feedback sections and the more elaborate the writing is, the higher a respective metric will be scored in the end. However, these parts often contain generic text pieces that are given as feedback to all students in a course. While this is important information for the student's final assessment, individual parts are more constructive and informative for the individual learning process and the continued development. That means, different feedbacks for the same learning activity need to be compared and text-matching algorithms will help indicate how many generic parts the teacher feedback contains, and where and to what extent the teacher goes into specifics and details about an individual student's achievements.

In summary, both content and form giving are assessable to a certain extent using the given metrics, which can be partly automatically derived from a database of teacher feedbacks, and partly need manual post-processing.

\section{DISCUSSION}

In this paper we have described the development of a framework for analyzing written feedback and the possibilities for translating this framework into indicators of feedback that can be directly queried with the education database.

Framework. The framework is funded in relevant literature on feedback and reflects the prevalent conceptions of what constitutes to good feedback in literature. However, mostly, good feedback is conceptualized as a two-sided dialogue in which both the teacher and the student play their part. Using the framework reduces feedback to a one-sided process in which the students' response is ignored. It can be argued that such an approach does no justice to the personal nature of learning and powerful feedback and cannot provide insight in the actual effects of written feedback. On the other hand, a one-sided approach can improve understanding in how the feedback is written.

Metrics. The metrics are not yet tested and further development will most likely show that some of the metrics cannot be as sharp as desired, or even need to be changed or abandoned. Still, the translation of teacher feedback literature to the conceptual framework and then further towards text-based indicators is a promising step for a highly automated analysis of the large-scale corpus of teacher feedback data.

\section{CONCLUSIONS}

The work in this paper is clearly work in progress. Based on the development of the framework and the exploration of developing metrics we can conclude that it is possible to translate the framework into metrics of feedback quality that can be directly queried with the education database.

Analyzing textual teacher feedback in an automated way is a difficult task as it attempts to quantize nuances of elaborate feedback, intricacies of language, intended ambiguities and humor into metrics that are directly comparable and also assessable. This relates back to the title of the paper: analyzing teacher feedback can be seen as feeding an administrative, controlling monster ever hungry and using generated data in a threatening way, but also as a large-scale to improve teacher feedback thoroughly, and to prove that the improvements are effective and beneficial.

An aspect that is currently not assessable using the feedback corpus is how students perceive and work with the teacher feedback. While analysis with synthetic metrics is a good approach to derive more objective quality measures from educational big data, only student feedback on how helpful, rich, and insightful the teacher feedback can provide future directions for improving feedback mechanisms on a large scale.

Based on the findings of applying the framework to the corpus of feedback data, we intend to design a (formative assessment or visual analysis) tool to be used by teachers and their students to assess the quality of their written feedback and start conversations about this feedback. In such meetings, it is possible for teachers to discover how their written feedback is actually perceived by students and what aspects of their written feedback really contribute to students' learning. Ideally we aim at structuring feedback processes like conversations, in which personal feedback is not only given and then received, but in which feedback is constructed in a joint process involving both (groups of) teacher(s) and students.

\section{REFERENCES}

[1] Black, P., \& Wiliam, D. (1998). Assessment and classroom learning. Assessment in Education, 5, 7-74.

[2] Hattie, J., \& Timperley, H. (2007). The power of feedback. Review of Educational Research, 77, 81-112.

[3] Perera, J., Lee, N., Win, K., Perera, J., \& Wijesuriya, L. (2008). Formative feedback to students: The mismatch between faculty perceptions and student expectations. Medical Teacher, 30, 395-399.

[4] Ferguson, P. (2011). Student perceptions of quality feedback in teacher education. Assessment \& Evaluation in Higher Education, 36, 51-62.

[5] Walker, M. (2006). An Investigation into written comments on assignments: Do students find them usable? Assessment and Evaluation in Higher Education, 34(1), 67-78

[6] Nicol, D. (2010) 'From monologue to dialogue: improving written feedback processes in mass higher education'. Assessment and Evaluation in Higher Education 35: 501-17.

[7] Shute, V. J. (2008). Focus on formative feedback. Review of Educational Research, 78, 153-189.

[8] Zimmerman, B. J. (2000). Attaining self-regulation and academic achievement. Theoretical Perspectives ( $2^{\text {nd }}$ ed.). Mahwah, Lawrence Erlbaum Associates. 
[9] Van Diggelen, M. R., den Brok, P. J., \& Beijaard, D. (2009). Creating a self-assessment instrument for teachers' coaching competence of vocational students' reflection skills: towards standards and criteria. Paper presented at the European
Association for Research on Learning and Instruction (EARLI). Amsterdam. 